\title{
LOS RIESGOS EN LA REDACCIÓN TÉCNICA ${ }^{1}$
}

\section{RISKS IN TECHNICAL WRITING}

\section{Denis Campos González*}

RESUMEN

El artículo proporciona información relacionada con los aspectos normativos de la legislación nacional costarricense y reglamentaria de la Universidad de Costa Rica, dedicados a la protección de los derechos de autor y derechos conexos y los recaudos que deben observarse al realizar un trabajo académico o intelectual para salvaguardar su integridad amén de la actitud de honestidad metodológica que debe caracterizar la labor de investigación.

\section{PALABRAS CLAVES: COSTA RICA * PROPIEDAD INTELECTUAL *LEGISLACIÓN * DERECHOS DE AUTOR * INVESTIGACIÓN}

\section{ABSTRACT}

The article provides information on the regulatory aspects of national legislation and regulations of Universidad de Costa Rica, dedicated to the protection of copyright and related rights and the precautions to be observed when making an intellectual or scholarly work to safeguard their integrity as well as the methodological attitude of honesty that characterize the research.

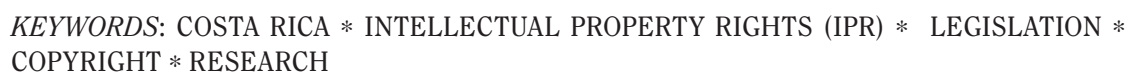

$1 \quad$ Ponencia presentada en el Auditorio de la Facultad de Agronomía el 22 de setiembre de 2008 y el 13 de abril de 2009 en el marco del "Seminario de Agronomía” sigla "AF-5413" coordinado por el Ing. Jorge A. Leiva M.Sc., Investigador del Centro de Investigaciones Agronómicas. El mencionado curso es un espacio para que los estudiantes de Agronomía desarrollen su trabajo final de graduación de licenciatura, por lo que los temas de derechos de autor, fraude literario y métodos $y$ técnicas de investigación resultan de interés, tanto para ellos como para los profesores que en su oportunidad han participado de la actividad que ha tenido carácter abierto. Posteriormente el texto ha sido revisado y ampliado a la luz de los dictámenes VI-2843-2009 y VI-2843-2009 elaborados por el autor, en el que se han estudiado diversos tópicos de los derechos de autor en el contexto universitario, tales como las implicaciones de la responsabilidad por disputas ocasionadas por la autoría de los artículos o parte de ellos que sean publicados en las revistas de la Universidad en sus diversos soportes mediando contratos de edición o sin ellos y otros aspectos de su regulación. Asimismo, incorpora elementos de otras discusiones como la contenida en el dictamen VI-1973-2009 relacionada con el alcance de los derechos de autor y el equilibrio que debe existir en relación con los derechos e intereses sociales de acceso a la cultura, a la educación y a la información.

* Asesor Legal de la Vicerrectoría de Investigación de la Universidad de Costa Rica. denis.campos@ucr.ac.cr 


\section{PLANTEAMIENTO DEL PROBLEMA}

Reconocer y afrontar la "apropiación ilegítima de la forma de expresión de las ideas ajenas" en el trabajo académico o intelectual es un imperativo para las instituciones de educación superior, toda vez que si estas prácticas, calificadas comúnmente como plagio no se rechazan enérgicamente, se generalizan y propagan, volviéndose comunes.

Si este tipo de prácticas fraudulentas se toleran, se promueven implícitamente la pereza, la renuncia a la creación y difusión de pensamiento original y efectivo; así como la deshonestidad metodológica e intelectual. Estas conductas $y$ actitudes van en detrimento no sólo de los intereses legítimos y los derechos subjetivos de los verdaderos autores, sino del desarrollo de la capacidad crítica, creativa y expresiva de los estudiantes, profesores e investigadores, $y$ de la verdadera producción de conocimiento, lo cual debe ser un objetivo primordial y permanente de cualquier universidad que aspire a ser más que un espacio para la divulgación acrítica de conocimientos.

El término plagio es un vocablo polisémico, con dos significados absolutamente diferentes que proceden de la tradición jurídica romana, y cuyo significado concreto debe ser resuelto por la particular definición que el derecho positivo le otorgue, en cada contexto normativo particular.

La primera acepción tiene que ver con el delito contra la libertad de las personas. Más ajustado con este contenido histórico, el Código Penal costarricense lo recoge en su artículo 189 como la reducción y mantenimiento de una persona a una condición de servidumbre u otra análoga. Sus orígenes se remontan al Derecho Romano, en el cual según:

... la Ley Fabia, se llamaba ["Plagiator"] a quien hubiera secuestrado a una persona libre, o que la hubiera vendido, comprado, o bien, a quien hubiera inducido a un esclavo a huir de su dueño, o dado refugio a aquél, o facilitado su fuga o cometido otros delitos congéneres que nada tienen de común con el latrocinio literario. En esta legislación, de finales del período republicano romano, el "plagium" se refería al crimen de rapto de hombres libres para reducirlos a la esclavitud, lo mismo que a la sustracción de esclavos. Estos delitos se castigaban con la deportación a las minas o la pena de muerte $^{2}$.

Esta forma de plagio evidentemente no tiene nada que ver con la violación de los derechos de autor. ¿Por qué entonces esta aparente confusión? Para explicar este punto debe analizarse el origen etimológico del concepto $y$ el uso que de él hace cierta parte de la doctrina y la receptación positiva que del concepto hacen ciertas legislaciones, por ejemplo la argentina. "[E]l término "plagium", "Plagiator" deriva del griego plagios que significa dolo o fraude y se adapta a los que cometen hurto intelectual con medios fraudulentos"3.

Así las cosas, en la actualidad, el vocablo "plagio" se utiliza indistintamente para hacer referencia a la infracción de los Derechos de Autor por usurpación de paternidad y por copia, como para hacer referencia al secuestro de personas ${ }^{4}$.

Balbuena, siguiendo en este punto a Della Costa, con el propósito de justificar esta afirmación señala:

En el rapto o seducción de un esclavo, y a su vez el vocablo alude a la 'plaga',

2 Ver Balbuena, Pedro Virgilio. "El plagio como ilícito penal”. (en línea) Ventana Legal Revista (VentanaLegal.com). En: < http://www.ventanalegal.com/revista_ventanalegal/plagio_ilicito.htm $>$ Este autor citando a Chaves, Antonio (El plagio. Memorias del I Congreso Internacional sobre la Protección de los Derechos Intelectuales (en homenaje a la memoria de Roberto Goldschmidt). Universidad Católica "Andrés Bello". Caracas. 1986).

3 Algardi. Citado por Latorre, Virgilio. Protección Penal del Derecho de Autor. 1ra. Ed. Tirant Lo Blanch. Valencia. 1994: 173. Citado por Balbuena, Ibid.

4 Balbuena, Ibid. 
es decir, a la red, lazo o trampa en que material o figuradamente, se lo hacía caer.//El símil es más acertado de lo que a primera vista parece porque, además del carácter insidioso que le es propio, $y$ que lo diferencia de las hipótesis normales de hurto y sus variantes, esa insidia o maquinación no recae en la persona damnificada, como el caso de la estafa, sino que actúa directamente sobre el objeto; en efecto, esa maquinación no se dirigía, en el antiguo precedente, a engañar al amo, sino al esclavo mismo, de igual manera que en el "plagio" autoral ella no incide de modo alguno sobre la voluntad del autor. Así como aquel se verificaba 'nesciente dominio', de una forma subrepticia, este tiene lugar 'nesciente auctore'. Y así como las señas visibles de la propiedad del esclavo debían ser cambiadas para aparentar su pertenencia al plagiario, en nuestro caso la obra sufre más o menos hábiles trasmutaciones técnicas que la presentan con visos de originalidad"5.

De lo anterior se colige que en Costa Rica, hasta la fecha, la apropiación ilegítima de la forma de expresión de las ideas ajenas no está explícitamente definida o tipificada como plagio. De tal forma que puede afirmarse que en el contexto jurídico nacional, la utilización de ese concepto para referirse a las hipótesis de violación de derechos de autor, a diferencia de lo que ocurre en Argentina, $y$ pese a lo extendido del término, resulta equívoca y atécnica, siendo lo correcto utilizar una expresión distinta que sea consistente con la legislación nacional sobre la materia.

$¿$ Quiere esto decir que no existen formas de protección para la apropiación ilegítima de la forma de expresión de las ideas ajenas en la legislación nacional?

La respuesta es obviamente negativa como se verá más adelante, pero lo cierto es

5 Della Costa, Héctor. El derecho de autor y su novedad. Buenos Aires. Cathedra, 1971: 199-200, citado por Balbuena, op. cit. que utilizando fórmulas diferentes, puesto que como se ha podido ver el concepto plagio en el ordenamiento costarricense tiene un contenido distinto. Por esta razón, es que el análisis debe reorientarse por las sendas conceptuales adecuadas, al ordenamiento nacional.

\section{TRATAMIENTO LEGAL DEL TEMA EN EL ORDENAMIENTO COSTARRICENSE}

\section{ASPECTOS GENERALES DE LA REGULACIÓN}

El campo de la propiedad intelectual suele dividirse para efectos de estudio y protección, en dos grandes áreas. De un lado se agrupan los derechos de autor $y$ derechos conexos $y$ de otro los derechos de propiedad industrial. Esta doble clasificación responde a la formación y origen de los criterios de protección europeos, que se remontan al Convenio de París para la Protección de la Propiedad Industrial (del 20 de marzo de 1883) y al Convenio de Berna para la Protección de las Obras Literarias y Artísticas (9 de septiembre de 1886), a partir de los cuales se escindió en estas dos grandes áreas de protección y se continuó regulando de esta manera a escala internacional y en las legislaciones domésticas.

En este breve desarrollo sólo se abordan algunos aspectos relativos a los derechos de autor y derechos conexos, no así a los derechos de propiedad intelectual, que podrían ser objeto de futuros análisis.

Ahora bien, de manera consistente con lo indicado, en el campo internacional, pueden encontrarse múltiples convenios internacionales que tutelan, específicamente, la materia de los derechos de autor $y$ derechos conexos los cuales Costa Rica ha ratificado incorporándolos a su ordenamiento interno mediante las respectivas leyes de las República, tal es el caso de los siguientes instrumentos:

$\diamond$ Convención Internacional sobre la protección de los artistas intérpretes o ejecutantes, los productores de fonogramas y los organismos de radiodifusión ("Convención de Roma, 1961"), aprobada mediante Ley nro. 4727 de 5 de marzo de 1971, publicada en $L a$ Gaceta nro. 59 del 13 de marzo de 1971. 
$\diamond$ Convención Universal sobre los Derechos de Autor ("Convención de Ginebra") y sus dos protocolos (París, 1971), aprobada mediante Ley nro. 5682 de 5 de mayo de 1975 publicada en el Alcance 83, La Gaceta nro. 103 del 4 de junio de 1975.

$\diamond$ Convenio de Berna para la protección de las obras literarias y artísticas, aprobado mediante Ley nro. 6083 de 29 de agosto de 1977 publicada en el Alcance 131, La Gaceta nro. 182 del 27 de setiembre de 1977.

$\diamond$ Tratado de la OMPI sobre Interpretación o Ejecución y Fonogramas (WPPT) (1996), Ley nro. 7967 de 22 de diciembre de 1999, publicada en La Gaceta nro. 21 del 31 de enero del 2000.

$\diamond$ Tratado de la OMPI sobre Derechos de Autor (WCT) (1996), Ley nro. 7968 de 22 de diciembre de 1999, publicada en La Gaceta nro. 23 del 2 de febrero del 2000.

$\diamond$ Convención para la protección de los productores de fonogramas contra la reproducción no autorizada de sus fonogramas, aprobada por Ley nro. 6486 de 25 de setiembre de 1980 publicada en La Gaceta nro. 212 del 5 de noviembre de 1980 .

$\diamond$ Convenio de Bruselas sobre la distribución de señales portadoras de programas transmitidas por satélite (1974), Ley nro. 7829 de 22 de setiembre de 1998 publicada en $L a$ Gaceta nro. 201 del 16 de octubre de 1998.

A los anteriores instrumentos internacionales hay que agregar la siguiente normativa interna, compuesta por leyes y decretos:

$\diamond$ Ley de Derechos de Autor y Derechos Conexos, Ley nro. 6683 de 14 de octubre de 1982 publicada en La Gaceta nro. 212 del 4 de noviembre de 1982 .

$\diamond$ Reforma a la Ley de Derechos de Autor y Derechos Conexos, Ley 7397 de 3 de mayo de 1994 publicada en La Gaceta nro.89 de 10 de mayo de 1994.

$\diamond$ Reglamento al artículo 50 de Ley de Derechos de Autor y Derechos Conexos, Decreto Ejecutivo nro. 23485-MP de 5 de julio de 1994.

$\diamond$ Interpretación auténtica de algunas disposiciones de la Ley de Derechos de Autor y
Derechos Conexos, Ley 7686 de 6 de agosto de 1997 publicada en La Gaceta 166 del 29 de agosto de 1997.

$\diamond$ Reformas a la Ley de Derechos de Autor y Derechos Conexos, nro. 6683 y sus Reformas, Ley de Patentes de Invención, Dibujos y Modelos Industriales y Modelos de Utilidad, nro. 6867 y sus Reformas y del Código Procesal Civil, Ley nro. 7130 y sus Reformas, Ley nro. 7979 del 6 de enero del 2000, publicada en La Gaceta nro. 21 del 31 de enero del 2000.

$\diamond$ Reglamento a la Ley de Derechos de Autor y Derechos Conexos, Decreto Ejecutivo nro. 24611-J de 4 de setiembre de 1995 publicado en el Diario Oficial el 24 de octubre de 1995.

$\diamond$ Reforma del Reglamento a la Ley de Derechos de Autor y Derechos Conexos, Decreto Ejecutivo nro. 26882-J de 20 de abril de 1998 publicado en el Diario Oficial de 20 de abril de 1998.

$\diamond$ Ley de Procedimientos de Observancia de los Derechos de Propiedad Intelectual nro. 8039 de 5 de octubre del 2000.

Todos estos instrumentos jurídicos contienen un sistema coherente de definición y protección de los derechos de autor y derechos conexos, en consonancia con los Tratados y Convenios Internacionales sobre la materia suscritos por nuestro país, contemplando incluso medidas de protección penal.

Es importante recalcar que, el objeto de la protección de los derechos de autor y derechos conexos es la expresión de las ideas y no las ideas propiamente dichas, las cuales se consideran un patrimonio colectivo y universal. Este concepto está recogido en el artículo $1^{\circ}$ de la Ley de Derechos de Autor y Derechos Conexos nro. 6683, el cual en lo que interesa señala que:

... [1]a protección del derecho de autor abarcará las expresiones, pero no las ideas, los procedimientos, métodos de operación ni los conceptos matemáticos en sí. Los autores son los titulares de los derechos patrimoniales $y$ morales sobre sus obras literarias o artísticas... 
Al respecto, es necesario indicar que la protección de los derechos de autor han sido elevados a la categoría de derechos humanos, $y$ como derecho fundamental está reconocido por la Constitución Política de Costa Rica en su Artículo 47 el cual a su tenor literal establece que:

Todo autor, inventor, productor o comerciante gozará temporalmente de la propiedad exclusiva de su obra, invención, marca, o nombre comercial con arreglo a la Ley (el destacado no es del original).

Asimismo, el Código Civil de Costa Rica apunta en su Artículo 275 que:

Las producciones del talento son una propiedad de su autor y se regirán por leyes especiales.

En este punto cobra importancia traer a colación el Artículo 4 de la Ley de Derechos de Autor y Derechos Conexos nro. 6683, el cual define reproducción fraudulenta como aquella no autorizada (inciso j), y como reproducción, aquella copia de obra literaria o artística o de una fijación visual o sonora, en forma parcial o total, en cualquier forma tangible, incluso cualquier almacenamiento permanente o temporal por medios electrónicos, aunque se trate de la realización bidimensional de una obra tridimensional o viceversa (inciso 1 ).

Ahora bien, el problema radica en reconocer cuándo se trata de una verdadera obra fraudulenta, o por el contrario, cuándo el autor de una obra se ha inspirado en ideas o situaciones previas, o si ha empleado conocimiento común o público (hechos o datos) que pueda encontrarse en diversas fuentes y que sea conocido por muchas personas o cuando ha hecho uso de un derecho legítimo de cita.

La inspiración es algo frecuente, está en las ideas en el ambiente o entorno cultural, por eso es que se ha indicado que las ideas son un patrimonio cultural. Un buen ejemplo son los famosos cuentos de los Hermanos Grimm, que son una recopilación de cuentos de hadas del folklore europeo que a su vez ha dado origen a múltiples adaptaciones y versiones: escritas para niños, para colorear, de crítica social, sátira, comedia, adaptaciones teatrales, cinematográficas, entre otras. Estos cuentos hoy por hoy se encuentran en el inconsciente colectivo de la sociedad occidental y son fuente de inspiración de mitos y tabúes, de temores y moralejas. Lo mismo valdría decir de obra como Las mil y una noche para salirse del entorno "occidental". Prácticamente cualquier persona podría utilizar estos relatos como fuente de inspiración, como idea central o secundaria para desarrollar cualquier otra que sea propia y original.

En relación con el conocimiento común o público, para utilizar una fórmula frecuente en el ámbito jurídico, puede decirse que es aquel que es evidente, manifiesto o notorio; es toda aquella información o simples datos ampliamente difundidos. Por ejemplo. $2+2=4$ ó $5 * 5=$ 25 o la constante de la gravedad es aproximadamente 9,8 ó la fórmula del agua es $\mathrm{H}_{2} \mathrm{O}$. Todos estos son datos o información, dependiendo del contexto, que es conocida prácticamente por todos los que tengan un mínimo de educación, general o básica. Estos no requieren de una fuente o una cita. También se incluyen aquellos contenidos en listados públicos como las guías telefónicas.

Además están aquellos que pertenecen al dominio público, sea porque ya se han extinguido los plazos de protección o porque ha operado una renuncia de su titular o cualquier otra causa legal, o porque su destino siempre fue el demanio. En ese sentido, su utilización no infringe derecho alguno. Aunque ética y metodológicamente lo recomendable sea citar su fuente, pero ese es un aspecto que trasciende lo legal y cae en el académico o científico.

Como puede apreciarse el hecho de que no esté absolutamente vedada la posibilidad de utilizar el pensamiento ajeno ofrece una serie de dificultades prácticas que obliga a realizar un análisis casuístico, crítico y sobre todo riguroso de las diferentes obras que se encuentren bajo evaluación, siempre reconociendo los inconvenientes prácticos para determinar los límites precisos de la noción jurídica y extrajurídica de los usos legítimos de una obra ajena o en su defecto si se trata de una obra fraudulenta, calificativo que sería el apropiado en el medio costarricense en lugar de "plagio". 
En el sentido apuntado, la Ley de Procedimientos de Observancia de los Derechos de Propiedad Intelectual, establece los mecanismos concretos de protección, en lo que interesa señala:

Artículo 1. Ámbito de aplicación.

La violación de cualquier derecho sobre la propiedad intelectual establecido en la legislación nacional o en convenios internacionales vigentes, dará lugar al ejercicio de las acciones administrativas ejercidas ante el Registro de la Propiedad Industrial o el Registro Nacional de Derechos de Autor y Derechos Conexos $y$ de las acciones judiciales ordenadas en la presente Ley, sin perjuicio de otras disposiciones del ordenamiento jurídico. Asimismo, esta Ley regulará la competencia del Tribunal Registral Administrativo en cuanto a las apelaciones de todos los registros del Registro Nacional...

\section{FUNDAMENTO DE LA PROTECCIÓN: EL BIEN JURÍDICO TUTELADO}

De previo es importante resaltar que las obras artísticas, literarias o científicas son una proyección del espíritu humano, $y$ en ese tanto reciben la protección del ordenamiento por el sólo hecho de su producción (es decir, de su existencia), sin que sea estrictamente necesario realizar ningún tipo de formalidad al efecto. En este sentido, la Ley de Derechos de Autor y Derechos Conexos dispone:

\section{Artículo 101}

La protección prevista en la presente ley lo es por el simple hecho de la creación independiente de cualquier formalidad 0 solemnidad.

El criterio de relevancia jurídica del fenómeno que se viene analizando es la infracción de los derechos morales y patrimoniales reco- nocidos por los ordenamientos jurídicos modernos, y elevado a rango de derecho fundamental en distintos instrumentos internacionales ${ }^{6}$.

En este sentido, la Ley de Derechos de Autor y Derechos Conexos, establece en sus numerales 13 y 14, lo siguiente:

\section{Artículo 13}

Independientemente de sus derechos patrimoniales, incluso después de su cesión, el autor conservará sobre la obra un derecho personalísimo, inalienable e irrenunciable $y$ perpetuo, denominado derecho moral.

\section{Artículo 14}

a) A menos que se acuerde de otra manera, mantener la obra inédita, pudiendo aplazar, por testamento, su publicación y reproducción durante un lapso hasta la cincuenta (50) años posteriores a su muerte.

b) Reivindicar la autoría de la obra.

c) Oponerse a cualquier deformación, mutilación u otra modificación de la obra o a cualquier atentado a esta que cause perjucio a su honor o a su reputación.

d) A menos que se acuerde de otra manera, retirar la obra de la circulación, previa indemnización a los perjudicados con su acción.

Los derechos morales son independientes de los derechos patrimoniales del autor. Los derechos mencionados en los incisos a) y d) anteriores, solo serán ejercitados una vez que se haya pagado una compensación apropiada a los terceros que puedan ser afectados por

Ver Balbuena, op.cit. Así por ejemplo el reconocimiento del Derecho de Autor como Derecho Humano mediante su incorporación en la Declaración Universal de Derechos del Hombre (art.27), y su reconocimiento en la Declaración Americana de los Derechos y Deberes del Hombre (art. XII), ambas declaraciones del año 1948. 
dichas acciones, a menos que se acuerde de otra manera.

El inciso a) se refiere a la que doctrinalmente se conoce como derecho de divulgación, el inciso b) recoge el derecho a la paternidad; el inciso c) responde al denominado derecho a la integridad de la obra y el inciso d) el derecho de retracto o arrepentimiento ${ }^{7}$.

Sin mucha dificultad puede apreciarse que la apropiación de las expresiones del conocimiento ajeno, vulnera todo este elenco de derechos al privar al verdadero autor de la posibilidad de ejercer su derecho de divulgación por el desconocimiento absoluto sobre el destino de la obra fraudulenta, así como su paternidad sobre la obra, al sustituirlo. De igual forma, el derecho a la integridad de la obra resulta groseramente infringido no sólo por las modificaciones o reformulaciones que pueden ser necesarias para hacer parecer el trabajo ajeno como propio, sino también por su inclusión en un discurso distinto al original, en el cual no sólo desde el punto de vista material, sino también ideológico (en sentido amplio) el sentido de la obra defraudada podría resultar mutilado. Lo mismo vale señalar respecto al derecho de retracto o arrepentimiento, pues el autor verdadero pierde todo control sobre el destino de su obra, que ha sido falseada o incorporada de manera ilegítima dentro de otra obra ${ }^{8}$.

Vale resaltar la ausencia de contenido económico del derecho moral del autor, el cual más bien se deriva de la vinculación personalísima de su titular con respecto a su obra. En contraposición a esto se ubica el derecho patrimonial del autor, cuyo alcance se define con arreglo al Reglamento a Ley de Derechos de Autor y Derechos Conexos 24611-J, en los siguientes términos:

\section{Artículo 28}

El derecho patrimonial comprende, especialmente, la modificación, la comunicación pública, la reproducción, la distribución y el

Para un desarrollo amplio de estos derechos ver Balbuena, op. cit.

Para un desarrollo amplio de esta idea ver Balbuena, op. cit. derecho de persecución ("droit de suite"), así como cualquier otra forma de utilización, proceso o sistema, conocido o por conocerse.

La Ley de Derechos de Autor y Derechos Conexos más adelante regula la enajenación y la transferibilidad de los derechos patrimoniales de autor al establecer que:

\section{Artículo 88}

El titular de derechos de autor o conexos puede enajenar, total o parcialmente, sus derechos patrimoniales.

\section{Artículo 89}

Todo acto de enajenación de una obra literaria o artística o de derecho conexo, sea total o parcial, deberá constar en instrumento público o privado, ante dos testigos.

Al tenor de las citas que se han reseñado es claro que la protección está destinada a garantizar el disfrute $y$ ejercicio exclusivo $y$ efectivo de las facultades otorgadas por los derechos moral y patrimonial que corresponden a su titular, las cuales vuelven nugatorias la acción del defraudador.

Es necesario señalar que la legislación de protección costarricense posee un marcado sesgo comercial, en particular los mecanismos de protección contenidos en la Ley de Procedimientos de Observancia de los Derechos de Derechos de Autor y Derechos Conexos y aunque sí brinda líneas de interpretación general respecto a los derechos de autor para el diseño, vía reglamentaria, de normativa apropiada, no está diseñada para la protección en el ámbito académico.

Salvo por lo indicado respecto a la libertad de cátedra en el artículo 87 de la Constitución Política en lo que interesa el artículo 40 de la Ley de Derechos de Autor y Derechos Conexos establece que

\section{Artículo 40}

Cuando uno o varios autores se comprometen a componer una obra, según 
plan suministrado por el editor, únicamente pueden pretender los honorarios convenidos. El comitente será el titular de los derechos patrimoniales sobre la obra, pero los comisarios conservarán sobre ella sus derechos morales; asimismo, cuando el autor sea un asalariado el titular de los derechos patrimoniales será el empleador. (el énfasis no es del original)

De conformidad con la norma los autores conservan sólo los derechos morales sobre sus obras, pero los derechos patrimoniales pasan a ser del editor o del empleador, según sea el caso. Esta norma es de especial relevancia para las Unidades Académicas y las Unidades Académicas de Investigación de la Universidad.

Existe norma especial en lo que se denomina en doctrina "sistema de titularidad" o de "apropiación" (Universidad de Costa Rica, Facultad de Derecho y Programa de Educación Continua, Primer Seminario Internacional de propiedad Industrial, Intelectual y Nuevas Tecnologías, Romano (Rubén), Transferencia de Tecnología y Propiedad de los Resultados de la Investigación en los Centros Universitarios. Titularidad y Transferencia de Tecnología, setiembre 2007) regulado en el artículo 16 del "Reglamento a la Ley de Derechos de Autor y Derechos Conexos No. 24611-J" que viene a reforzar esta norma legal, relativo a la apropiación de las obras artísticas o literarias realizadas en el marco de un contrato de trabajo o de función pública para un ente o sujeto de Derecho Público, la cual dispone lo siguiente:

\section{Artículo 16}

En las obras creadas para una persona natural o jurídica, en cumplimiento de un contrato de trabajo o en ejercicio de una función pública, el titular originario de los derechos morales y patrimoniales es el autor, pero se presume, salvo pacto en contrario, que el derecho patrimonial o de utilización ha sido cedido al empleador o al ente de Derecho Público, según los casos, en la medida necesaria para sus actividades habituales en la época de la creación de la obra, lo que implica, igualmente, la autorización para divulgarla y para defender los derechos morales en cuanto sea necesario para la explotación de la misma.

El fin (teleológico) de la norma es la protección de los fondos públicos destinados al financiamiento de las producciones artísticas o literarias, para salvaguardar el conocimiento producido en las Instituciones Públicas por los distintos funcionarios quienes podrían argumentar que el mismo les pertenece, obviando no sólo el aporte institucional, sino sus obligaciones laborales y sus obligaciones con la sociedad costarricense, con el riesgo y amenaza de privatizar ese conocimiento indebidamente.

Debe recalcarse que los funcionarios, (sean estos administrativos o docentes, en el caso de la Universidad) mantendrán los derechos morales, pero por desarrollarse en el marco de una relación de empleo (laboral propiamente dicha o de función pública), tales derechos serán compartidos con las Instituciones a las que sirven $y$ los derechos patrimoniales pertenecerán a estas exclusivamente. Salvo pacto en contrario, no pudiendo invocar la exclusividad o la facultad de divulgación que cede en este caso ante los fines para los cuales fue desarrollada la obra en el marco de la relación de empleo o relación funcionarial para la satisfacción de las necesidades de la Administración Pública, la cual pagó por ella a través del respectivo salario $\mathrm{u}$ honorario si se trataba de una relación de servicios profesionales.

Más bien, si la labor tenía un determinado plazo de entrega que era de conocimiento anticipado del funcionario y este no cumplió, satisfactoriamente, con lo mandado y pagado, podría encontrarse ante hipótesis de incumplimiento que sería necesario evaluar casuísticamente a la luz de un debido proceso. Esta situación se agravaría aún más si con ello se pone en situación de incumplimiento a la institución frente a terceros por compromisos adquiridos en un contrato o convenio, casos en los que se puede engendrar una responsabilidad para la institución, pero en los que más allá de 
la responsabilidad jurídica propiamente dicha, se encuentra su prestigio y su imagen.

En tal sentido, las interrogantes planteadas han sido objeto de abordaje por parte de la Sala Segunda de la Corte Suprema de Justicia la cual ha confirmado las impresiones que hasta aquí se han expuesto, con la ventaja de exponer cómo se concilian varios temas que merecen una respuesta y que hasta el momento podrían ser motivo de duda. En primer término, cómo resolver el conflicto entre los derechos de los autores, entendidos como derecho especial absoluto, frente a la enajenación que sufren por efecto de la venta de su fuerza de trabajo $y$, de otro lado, como llevar el tema de análisis de la esfera de la relación laboral a la esfera de los servicios profesionales. Estos temas se abordan en la resolución de la Sala Segunda, No. 415 de las 09 horas del 22 de diciembre de $1994^{9}$. El desarrollo de estos temas rebasaría el objeto de estas breves notas, para mayor detalles puede consultarse la sentencia y la bibliografía citada, aunque debe advertirse que los criterios no son pacíficos.

A continuación se pasa revista de las normas más relevantes que ilustran el tratamiento legal del latrocinio literario, como lo denomina la doctrina, en el ordenamiento nacional.

Como se ha visto, las prohibiciones totales no tendrían sentido, $y$ más bien obstaculizarían el desarrollo académico, científico, artístico y humano en general. Las ideas son un patrimonio universal. Las formas de investigar, el estado actual del conocimiento, $y$ en general del espíritu humano, son el resultado de la difusión de las ideas de los pensadores y científicos en todas las ramas, que influyen en el estado actual del conocimiento, $y$ cuya información es de hecho utilizada en la vida cotidiana por todas las personas, con independencia de los niveles académicos y los propósitos de cada quién.

De igual forma, a modo de ejemplo, pueden citarse los artículos 54 y 57 de la Ley de

Citado por Castro Lobo, Manuel. Derechos de autor $y$ derechos conexos en Costa Rica. San José. Alma Mater. 1. ed. 1999. p. 81-92. Debe señalarse que las conclusiones a las que llega el autor citado tras el comentario de esta sentencia son diametralmente opuestas a las sostenidas en este desarrollo.
Procedimientos de Observancia de los Derechos de Propiedad Intelectual, que castigan desde la perspectiva penal la Reproducción no autorizada de obras literarias o artísticas o fonogramas y la Publicación como propias de obras ajenas, pero dejan a salvo (es decir, que consideran no punible) la reproducción sin fines de lucro de obras literarias o artísticas, la reproducción de fonogramas, $y$ la utilización de obras literarias o artísticas en la medida requerida para cumplir fines ilustrativos para la enseñanza, con tal de que esa reproducción sea conforme a los usos debidos y que se mencione la fuente $y$ el nombre del autor, si este nombre figura en la fuente.

Para lograr un criterio informado de cara a establecer este tipo de juicios, que en ciertos casos podrían resultar nada sencillos, es necesario analizar las excepciones contempladas en la legislación nacional y en particular lo relacionado con el denominado derecho de cita.

\section{EL DERECHO DE CITA}

A los efectos de introducir este tema resulta valioso e informativo traer a colación el criterio de la Comisión Interinstitucional de Propiedad Intelectual, que en su Comunicado del 17 de marzo de 2009 dirigido a la Comunidad Nacional, con el fin de aclarar el contenido $y$ alcance de la normativa vigente en el país, que regula los derechos de autor y derechos conexos y las excepciones a los mismos, a los diferentes actores involucrados y al público en general, señaló

... [1]a legislación costarricense en materia de derechos de autor establece un marco sólido de protección a estos derechos, buscando un adecuado equilibrio entre los derechos de los creadores de obras y los derechos e intereses de la sociedad en general, incluyendo el acceso a la educación, a la cultura y a la información. Con este objetivo en mente la legislación nacional, otorga por una parte, una serie de derechos exclusivos a los autores de obras literarias $y$ artísticas y establece, por otra, excepciones limitadas 
a estos derechos para permitir su uso y reproducción con fines educativos. (...)

En términos generales, dichas excepciones para fines educativos son permitidas siempre que se cumplan cuatro condiciones básicas:

$\diamond$ Que no medie un ánimo de lucro por parte del usuario.

$\diamond$ Que la utilización se dé en la medida necesaria para cumplir con los fines educativos.

$\diamond$ Que se cite la fuente y el nombre del autor.

$\diamond$ Que la utilización o reproducción sea conforme a los usos debidos. Esta última condición se cumple en el tanto el uso o reproducción de la obra no afecte la explotación normal de la obra en cuestión ni cause un perjuicio injustificado a los intereses legítimos del autor $^{10}$.

Dentro del elenco de excepciones a los derechos exclusivos del autor, contempladas por la legislación vigente en Costa Rica, se pueden citar:

$\diamond$ El Derecho de Cita (Artículo 70 LDADC).

$\diamond$ La utilización de la obra para la enseñanza (Artículo 73 bis d) LDADC).

$\diamond$ La reproducción de los artículos de actualidad (73 bis b) LDADC).

$\diamond$ La utilización accidental $\mathrm{u}$ incidental de una obra (73 bis c) LDADC).

$\diamond$ La utilización de obras orales (73 y 75 LDADC).

$\diamond$ El uso privado (73 bis a) en relación con el 74 LDADC).

$\diamond$ La reproducción de obras artísticas ubicadas permanentemente en sitios públicos.

$\diamond$ La reproducción de obras por el sistema braille u otro procedimiento análogo.

10 Comunicado de la Comisión Interinstitucional de Propiedad Intelectual en el cual hace aclaraciones sobre los principales alcances de la legislación de derechos de autor en materia de reproducción de obras literarias con fines educativos, 17 de marzo de 2009 (en línea). En: <http://www.informa-tico. com/index.php?scc $=$ articulo\&edicion $=20090318 \&$ ref $=18-03-09020002>$. $\diamond$ Otras excepciones, tales como la reproducción irrestricta de la normativa nacional (Artículo 75 LDADC).

$\diamond$ Las licencias obligatorias, consagrada bajo hipótesis extravagantes en los tratados de Berna y en la Convención Universal, siempre que sean utilizadas con fines estrictamente académicos, universitarios o investigativos.

$\diamond$ Duración de la Protección. La protección propuesta busca que los creadores tengan un estímulo en el cual reciban beneficios económicos por su esfuerzo. Pero al mismo tiempo, en un afán de lograr un equilibrio entre el disfrute o resarcimiento personal y el acceso colectivo al conocimiento, dicha protección expira y la obra ingresa dentro de los bienes de dominio público.

De todas estas excepciones, la que interesa analizar con detalle el derecho de cita a los efectos de la presente exposición, sin perjuicio de realizar algunos apuntes sobre las otras formas. Esta excepción implica que pueden emplearse ciertas partes de una obra siempre que se dé el debido crédito a su autor, como consecuencia de su derecho moral; respetando ciertas características sobre las que en realidad no existe uniformidad de criterio entre la doctrina propiamente técnica y la jurídica, que hacen referencia a la brevedad de la referencia, aunque esto es variable.

El Convenio de Berna en sus artículos 10 y 10 bis, regulan el equilibrio que debe existir entre la protección al derecho de autor y la licitud del denominado derecho de cita, en los siguientes términos:

\section{Artículo 10}

1. Son lícitas las citas tomadas de una obra que se haya hecho lícitamente accesible al público, a condición de que se hagan conforme a los usos honrados y en la medida justificada por el fin que se persiga, comprendiéndose las citas de artículos periodísticos y colecciones periódicas bajo la forma de revistas de Prensa.

2. Se reserva a las legislaciones de los países de la Unión y de los Arreglos particulares 
existentes o que se establezcan entre ellos lo que concierne a la facultad de utilizar lícitamente, en la medida justificada por el fin perseguido, las obras literarias o artísticas a título de ilustración de la enseñanza por medio de publicaciones, emisiones de radio o grabaciones sonoras o visuales, con tal de que esa utilización sea conforme a los usos honrados.

3. Las citas y utilizaciones a que se refieren los párrafos precedentes deberán mencionar la fuente y el nombre del autor, si este nombre figura en la fuente.

\section{$(\ldots)$}

\section{Artículo 10-bis}

1. Se reserva a las legislaciones de los países de la Unión la facultad de permitir la reproducción por la Prensa o la radiodifusión o la transmisión por hilo al público de los artículos de actualidad de discusión económica, política o religiosa publicados en periódicos o colecciones periódicas u obras radiodifundidas que tengan el mismo carácter, en los casos en que la reproducción, la radiodifusión o la expresada transmisión no se hayan reservado expresamente. Sin embargo, habrá que indicar siempre claramente la fuente; la sanción al incumplimiento de esta obligación será determinada por la legislación del país en el que se reclame la protección.

2. Queda igualmente reservada a las legislaciones de los países de la Unión la facultad de establecer las condiciones en que, con ocasión de las informaciones relativas a acontecimientos de actualidad por medio de la fotografía o de la cinematografía o por radiodifusión o transmisión por hilo al público, puedan ser reproducidas $y$ hechas accesibles al público, en la medida justificada por el fin de la información, las obras literarias o artísticas que hayan de ser vistas u oídas en el curso del acontecimiento...

Por su parte, el Derecho de Cita se encuentra regulado en la Ley de Derechos de Autor y Derechos Conexos nro. 6683 en el artículo 70 en los siguientes términos:

\section{Artículo 70 (*)}

Es permitido citar a un autor, transcribiendo los pasajes pertinentes de una obra que lícitamente haya sido puesta a disposición del público, siempre que estos no sean tantos y seguidos, que puedan considerarse como una reproducción simulada y sustancial, que redunde en un perjuicio del autor de la obra original, y su extensión no exceda la medida justificada por el fin que se persiga.

Las otras excepciones mencionadas supra, se pueden encontrar en los siguientes numerales de la Ley de Derechos de Autor y Derechos Conexos nro. 6683:

\section{Artículo 73 bis. (*)}

1. Son permitidas las siguientes excepciones a la protección prevista en esta Ley, para los derechos exclusivos de los artistas intérpretes o ejecutantes, los productores de fonogramas y los organismos de radiodifusión, siempre y cuando no atenten contra la explotación normal de la interpretación o ejecución, del fonograma o emisión, ni causen un perjuicio injustificado a los intereses legítimos del titular del derecho:

a) Cuando se trate de una utilización para uso privado.

b) Cuando se hayan utilizado breves fragmentos con motivo de informaciones sobre sucesos de actualidad.

c) Cuando se trate de una fijación efímera realizada por un organismo de radiodifusión por sus propios medios y para sus propias emisiones.

d) Cuando se trate de una utilización con fines exclusivamente docentes o de investigación científica.

2. Sin perjuicio de lo dispuesto en el párrafo 1 de este artículo y en el artículo 83 de esta Ley, no es permitida la retransmisión de señales de televisión (ya sea terrestre, por cable o por satélite) en Internet sin la autorización del titular o los titulares del derecho sobre el contenido de la señal y de la señal. (...) 


\section{Artículo 74}

También es libre la reproducción de una obra didáctica o científica, efectuada personal y exclusivamente por el interesado para su propio uso y sin ningún ánimo de lucro, directo o indirecto. Esa reproducción deberá realizarse en un solo ejemplar, mecanografiado o manuscrito.

Esta disposición no se aplicará a los programas de computación.

\section{Artículo 75}

Se permite a todos reproducir, libremente, las constituciones, leyes, decretos, acuerdos municipales, reglamentos $y$ demás actos públicos, bajo la obligación de conformarse estrictamente con la edición oficial. Los particulares también pueden publicar los códigos y colecciones legislativas, con notas y comentarios, y cada autor será dueño de su propio trabajo.

\section{EL ABUSO DEL DERECHO DE CITA Y LA OBRA FRAUDULENTA}

Como todo derecho, el derecho de cita admite su abuso. Este abuso está claramente definido en el mismo numeral 70 de la Ley 6683 que establece que es permitida la cita a condición de que la transcripción de los pasajes sea pertinente. Como un segundo elemento que la obra haya sido puesta lícitamente a disposición del público. Un tercer elemento es que los pasajes transcritos no sean tantos y seguidos, que puedan considerarse como una reproducción simulada y sustancial, que redunde en un perjuicio del autor de la obra original, y que su extensión no exceda la medida justificada por el fin que se persiga. En otras palabras, impone un límite cuantitativo, supuestamente cuantificable, medible, aunque no especifica - la legislación costarricense- $y$ en tratándose de obras literarias, la cantidad de palabras, caracteres, cuartillas o cualquier otra unidad de medición que sirva de parámetro objetivo para juzgar la extensión lícita de la cita.

En todo caso, lo cierto es que la cita deberá estar justificada por los fines académicos que persigue y en ese tanto existe un margen de discrecionalidad en su apreciación, no arbitraria sino marcada por la racionalidad, la razonabilidad, la proporcionalidad y sobre todo por una valoración en doble vía:

a. De carácter ético en función del animus del agente, en el sentido de determinar que no se trató de una actitud deliberada del autor de la obra que actuando con dolo o culpa grave se apropió de ideas ajenas, incurriendo con tal conducta - reprochable - en una obra - total o parcialmente - fraudulenta.

b. De mérito y capacidad, para usar el término empleado por la propia Constitución Política en su numeral 191, con base en su idoneidad, en tal sentido, puede apreciarse en la conducta no tanto una intención de apropiarse indebidamente de las ideas ajenas, un animus nocendi, sino más bien una impericia del investigador, que bien puede requerir de apoyo, de mejores instrumentos metodológicos, mejorar aspectos formales como redacción, manejo de citas, entre otros.

Valga reiterar, que el artículo 4 de la Ley de Derechos de Autor y Derechos Conexos 6683, define reproducción fraudulenta como aquella no autorizada (inciso j), y como reproducción, aquella copia de obra literaria o artística o de una fijación visual o sonora, en forma parcial o total, en cualquier forma tangible, incluso cualquier almacenamiento permanente o temporal por medios electrónicos, aunque se trate de la realización bidimensional de una obra tridimensional o viceversa (inciso l).

\section{EL TRATAMIENTO DEL FRAUDE LITERARIO EN LA UNIVERSIDAD DE COSTA RICA}

En primer término, $y$ aunque resulte lógico, debe advertirse que el tratamiento del fraude literario debe ser diferente en el caso de que este sea cometido por un estudiante o por un profesor. 
Otra advertencia pertinente consiste en que deben diferenciarse las consecuencias lógicas de carácter académico o laboral, según sea el caso, que se derivan de la constatación de un fraude de este tipo y las eventuales consecuencias disciplinarias del mismo acto, del cual se derivarían (responderían) diferentes tipos de responsabilidad.

Es necesario aclarar que en el Anexo 1 del "Reglamento de Trabajos Finales de Graduación" contiene la única mención específica al tema de las citas bibliográficas y su regulación en la Universidad de Costa Rica, y de manera bastante lacónica señala que:

... En lo tocante a la información que las notas al pie de página $y$ las referencias bibliográficas deben suministrar, cada unidad académica establecerá las normas usuales en la disciplina correspondiente.

Para la ubicación de las notas al pie de página, o al final de cada capítulo, la Vicerrectoría recomienda una práctica metódica de cualquiera de las dos modalidades, como también admitirá el uso metódico de otros sistemas de presentación de la información bibliográfica, siempre que sean de amplio uso internacional y goce de la aprobación de la respectiva Comisión de Trabajos Finales de Graduación.

De lo expuesto se infiere que resulta discrecional para cada Unidad Académica y en particular para cada Comisión de Investigación de esas Unidades, regular estos aspectos y determinar o verificar el cumplimiento satisfactorio de los parámetros académicos en cada caso, previa valoración de los respectivos Comités Asesores y Tribunales de los Trabajos Finales de Graduación.

1. EL TRATAMIENTO DEL PROBLEMA EN EL CASO DE LOS ESTUDIANTES

El Reglamento de Orden y Disciplina Estudiantil de la Universidad de Costa Rica, no contenía hasta el 9 de diciembre de 2009, normas expresas relacionadas con el fraude literario. Es hasta esa reciente reforma que se incorpora la figura en los términos y con las acotaciones que se dirán. De previo a esa fecha la única norma que se entendía podía aplicarse de manera conexa a este tipo de hipótesis en lo que interesa señala:

\section{Artículo 5. Son faltas graves:}<smiles>[CH]1[CH]C1</smiles>

b) Procurarse por cualquier medio ilícito, en el momento de la realización de la prueba, examen o control de conocimientos cualquier tipo de información utilizable para ese efecto o del mismo modo suministrar a otro dicha información...

Esta era la única norma del sistema que se refería a un comportamiento punible referido al fraude cometido por un estudiante en el contexto “...de la realización de la prueba, examen o control de conocimientos..." Sobre el particular en el dictamen de referencia 0J-1271-2007 la Oficina Jurídica de la UCR, esbozó el siguiente análisis:

Este artículo califica como falta grave dos acciones distintas definidas por 1) "el procurarse... cualquier tipo de información" y 2) "suministrar a otro dicha información”.

Mientras que el objeto material de protección contemplado en la norma está definido por "pruebas, exámenes o controles de conocimientos". Este último resulta un concepto poco claro, constituye un concepto normativo que de no ser definido mediante una interpretación hegemónica de las autoridades universitarias, la norma quebrantaría el principio de tipicidad.

A partir de lo anterior, puede afirmarse que el bien jurídico contemplado en esta 
disposición es la integridad de la labor y la conducta estudiantil y la objetividad de las pruebas o mediciones de conocimiento.

Por su parte, las diferentes disposiciones y cuerpos normativos que dentro del derecho común regulan o protegen la propiedad intelectual o derechos de autor, poseen bienes jurídicos muy diferentes a los de la norma universitaria. Como bien se indica en los diferentes cuerpos normativos, esta rama del derecho promueve la protección a la propiedad privada, extendiendo dicho concepto a los productos o creaciones inmateriales del pensamiento humano.

De manera particular, el artículo 5 no menciona el fraude literario de propiedad intelectual ni en términos generales, ni en especial en trabajos de investigación o trabajos finales de graduación. Desde este punto de vista, una interpretación restrictiva del derecho sancionatorio $y$ según el principio de tipicidad aplicado en esta materia, vendría a excluir la posibilidad de utilizar la disposición del artículo 5 a efectos de sancionar el fraude literario $y$ proteger con ello la propiedad intelectual o derechos de autor.

Frente a esto y salvo mejor criterio de las Autoridades Universitarias, lo más recomendable es que se modifique el texto del artículo 5 inciso b), de manera que se concrete con mayor detalle, que debe entenderse por "control de conocimiento" incluyéndose el fraude literario como acción prohibida, según la protección pretendida para los bienes jurídicos, definidos en la norma universitaria.

Otra alternativa o complemento posible sería la inclusión de una nueva norma cuya acción prohibida sea específicamente el fraude literario y cuyo bien jurídico sea la propiedad intelectual $y$ derechos de autor contenida en obras literarias como revistas, libros, sitios web, entre otros (objeto material de protección).

De lo anterior se colige que en aplicación del principio nullum crimen nullum poena sine praevia lege penale, la posibilidad de incoar un procedimiento disciplinario estudiantil por fraude literario estaba vedada por la ausencia de una norma que tipificara tal acción o comportamiento como una falta.

La anterior conclusión no significa que el fraude literario pudiera o debiera quedar impune. Al respecto del análisis del tratamiento de los casos que se han presentado en la Universidad en los últimos años, se extraen dos vías de afrontamiento, según sea el momento en el que se detecte la anomalía.

\section{a) DESCUBRIMIENTO DEL FRAUDE LITERARIO DURANTE EL PROCESO DE EVALUACIÓN}

En el dictamen de referencia OJ-00292005, también de la Oficina Jurídica, en lo que interesa señaló que

la administración puede corregir este tipo de errores en cuanto tenga conocimiento de ellos, siempre que no haya otorgado el título y grado académico respectivo, en cuyo caso deberá seguir un procedimiento especial, sea en sede administrativa 0 jurisdiccional.

En la primera hipótesis, es decir cuando el fraude literario es descubierto durante la evaluación de las propuestas de investigación, se reconoce la legitimidad de un proceso por fraude literario

... que no pretenda la imposición de una sanción o castigo por las irregularidades detectadas, sino la producción de las consecuencias académicas lógicas de la constatación de las conductas señaladas, [tal como es] la corrección de la calificación otorgada bajo falsas premisas [a un 
determinado trabajo. También señala la posibilidad jurídica de realizar correcciones de las notas, aún en detrimento de los estudiantes toda vez que] en este tipo de materias el error no genera derecho $y$ no puede consolidarse la situación de un estudiante que no haya cumplido con los requisitos reglamentarios y académicos $y$ que haya incurrido en conductas que poco reflejan el espíritu universitario de búsqueda de la verdad y excelencia...

Otro aspecto relevante de estos dos pronunciamientos es que recogen la naturaleza de falta de "mera constatación de este tipo de circunstancias" por lo cual "las consecuencias lógicas que produzca no requieren la observancia del Debido Proceso" por no tratarse de la imposición de una sanción propia del Régimen Disciplinario.

De lo expuesto, a fortiori se colige que si mediante un proceso crítico de revisión se acredita la existencia de fraude literario en el trabajo de investigación de un estudiante, no sólo podría variarse una nota satisfactoria otorgada previamente a una que no lo sea (lo cual podría imponerse si el fraude literario es detectado tempranamente). De igual forma de tratarse de un trabajo final de graduación; está entre las potestades del Comité Asesor no declararlo listo o apto para su defensa hasta que dicha infracción sea corregida. En resumen, la consecuencia lógica académica del fraude literario es la mala calificación del reporte o trabajo de investigación de que se trate, con las consecuencias que tal situación le reporte al estudiante.

\section{b) DESCUBRIMIENTO DEL FRAUDE LITERARIO CON POSTERIORIDAD A LA DEFENSA Y APROBACIÓN DE UN TRABAJO FINAL DE GRADUACIÓN Y POSTERIOR ENTREGA DE DIPLOMA Y JURAMENTACIÓN}

Cuando un trabajo final de graduación que contiene un fraude literario no es detectado oportunamente, este se defiende públicamente $y$ constituye el sustento del otorgamiento del diploma respectivo y la juramentación de un estudiante, se puede estar ante nulidades absolutas, que a su vez pueden ser nulidades absolutas evidentes y manifiestas, o de nulidades nulidades absolutas que no ostenten el carácter de evidentes y manifiestas, las cuales, en atención al momento del descubrimiento, pueden considerarse actos administrativos declaratorios de derechos subjetivos que pueden ser anulados (i) de conformidad con el artículo 173 de la Ley General de la Administración Pública en sede administrativa, observando los principios del debido proceso, previo dictamen favorable de la Procuraduría General de la República o (ii) mediante el proceso judicial de lesividad en la jurisdicción contencioso administrativa. Todo lo anterior de conformidad con las pautas de la mencionada ley y las disposiciones conexas del Código Contencioso Administrativo (CPCA), concretamente el artículo 34 inciso 1) de este último cuerpo normativo. Para seguir la segunda vía es necesario que la institución, de manera motivada, declare lesivos al interés público los actos de aprobación de tesis, otorgamiento de título y juramentación. El plazo máximo para ello será de un año, contado a partir del día siguiente a aquel en que haya sido dictado, salvo si el acto contiene vicios de nulidad absoluta, en cuyo caso, dicha declaratoria podrá hacerse mientras perduren sus efectos. En este último supuesto, el plazo de un año correrá a partir de que cesen sus efectos y la sentencia que declare la nulidad lo hará, únicamente, para fines de su anulación e inaplicabilidad futura (Artículos 34 y 39 CPCA).

En el caso de los trabajos finales de graduación estas normas son de particular importancia, pues el fraude literario es un vicio de nulidad absoluta, que entraña varias violaciones, entre ellas la obligación personalísima de realizarlo por sí mismo, con exclusión de cualquier otro $y$ nunca por interpuesta persona, la investigación y en general las obligaciones académicas sujetas a evaluación, por lo tanto el de aprobación de tesis y los correlativos de otorgamiento de título y juramentación son actos cuyos efectos perduran en el tiempo, y podrían ser discutidos en vía judicial en un plazo no mayor a un año a partir del momento del descubrimiento de la falsedad, y la sentencia que declare la nulidad lo hará, únicamente, para fines de su anulación e inaplicabilidad futura, en aplicación de los artículos 34 y 39 CPCA. 
Hay que reconocer que esta tesis es discutible $y$ debe ser probada en estados judiciales. Sólo existe un precedente discutido a ese nivel, que fue declarado extemporáneo o caduco, pero debe aclararse que fue a la luz de la derogada Ley Reguladora de la Jurisdicción Contencioso Administrativa que no contenía la cláusula abierta que permite solicitar la nulidad de los actos mientras perduren sus efectos, como sí lo hace la ley vigente y en el caso concreto habían transcurrido más de 10 años. En la ley anterior, existía el sinsentido de que las nulidades absolutas se convalidaban, en contra de la lógica y la doctrina más reconocida, por un efecto práctico pasados 4 años. De lo expuesto cabe señalar que el control para el descubrimiento oportuno de este tipo de situaciones es de vital importancia aún hoy en día.

\section{c) LA INCLUSION DEL "PLAGIO" ENEL REGLAMENTO DE ORDEN Y DISCIPLINA DE LOS ESTUDIANTES DE LA UNIVERSIDAD DE COSTA RICA}

Como se señaló al principio, de este apartado, a partir del 9 de diciembre de 2009, se reformó el Reglamento de Orden y Disciplina de los Estudiantes de la Universidad de Costa Rica, en la sesión 5414-16 del Consejo Universitario, incluyendo los incisos j) y k) al artículo 4), que establece:

\section{Artículo 4. Son faltas muy graves:}

\section{$(\ldots)$}

j) Plagiar, en todo o en parte, obras intelectuales de cualquier tipo.

k) Presentar como propia una obra intelectual elaborada por otra $u$ otras personas, para cumplir con los requisitos de cursos, trabajos finales de graduación o actividades académicas similares.

Con las normas transcritas sin duda alguna se viene a superar una importante laguna jurídica $y$ se brinda a los operadores una norma habilitante para la persecución y sanción del fraude en el trabajo académico en el caso de los estudiantes, llevándolo incluso a la esfera disciplinaria con la categoría de falta grave y superando una falencia del sistema.

Desde el punto de vista técnico y desde una perspectiva sistemática del sistema, para ser consistente con el planteamiento de este trabajo, el vocablo "plagiar" como verbo que define la acción típica y culpable del tipo disciplinario responde a la comodidad y al uso extendido del término, pero no necesariamente, como se ha indicado a la largo de esta exposición a un adecuado uso técnico del concepto "plagio" en el ordenamiento nacional costarricense en la legislación de derechos de autor y propiedad intelectual y la legislación penal.

\section{2) EL TRATAMIENTO DEL PROBLEMA EN LA DOCENCIA}

En este caso a la luz del Régimen Disciplinario Docente vigente, no parece que el asunto pueda tratarse como una falta de servicio, salvo que se subsuma dentro de uno de los tipos abiertos. Eso implica un alto nivel de indefinición institucional. La última versión publicada en el Alcance, La Gaceta Universitaria 5-2008 del 11 de agosto de 2008, sin perjuicio de las modificaciones que requiere la normativa en materia de procedimientos para ser eficiente, contempla en su artículo 6 incisos s) y t) tipos que subsumen estos comportamientos y permiten sancionarlos como faltas graves. Lo que sí debe imponerse son las sanciones morales $y$ las consecuencias académicas lógicas como son la reprobación de los informes por parte de los Consejos Científicos, las Comisiones de Investigación de las Unidades Académicas o Académicas de Investigación, con las consecuentes medidas sobre la carga académica y disposiciones presupuestarias.

Para que estas normas sean eficaces requieren de voluntad política y enérgica de las autoridades competentes $y$ de todos los actores involucrados en su aplicación, un consenso en cuanto a la necesidad de su aplicación y respeto para que ante la identificación de las conductas se lleven a cabo las denuncias y el seguimiento en el marco de una política de cero tolerancia a la impunidad y para ser consecuentes, estar dispuestos a llegar hasta las últimas consecuencias 
con este tipo de procedimientos. Además de las causales expresamente reguladas existe sin duda alguna, una causal abierta de bajo desempeño, que sería necesario documentar y evaluar en el marco de un debido proceso. Y es que el tema cobra una relevancia significativa si se considera que quien ha incurrido en una especie de latrocinio literario, siendo investigador de una Universidad Estatal, no sólo ha faltado a la ética y violentado el patrimonio jurídico de un tercero particular. Ha defraudado al erario, pues la Universidad es una institución sufragada con fondos públicos y su salario es cargado a esos fondos. Su tiempo y su supuesto esfuerzo se le han remunerado con el propósito de que se dedique a la producción en un determinado campo del saber, $y$ por su condición académica su falta es calificada, puesto que ha incumplido gravemente sus obligaciones laborales y con ello el contenido ético de su contrato laboral.

Por eso la falta es grave, y en caso de que el tratamiento preventivo falle, debe existir mano dura en contra de quienes cometan acciones de este tipo $y$ debe aplicarse todo el rigor del caso, considerando no sólo las acciones de regreso para la recuperación de los daños y perjuicios en que haya hecho incurrir eventualmente a la Universidad, el responsable con sus acciones, no sólo a título de costos directos, sino también por concepto de costos indirectos como podría ser la afectación de la imagen institucional al verse envuelta en eventuales disputas con terceros por los derechos de autor si se han realizados publicaciones en los medios de la Universidad, con independencia de su soporte, ya sea en el marco de contratos de edición o sin ellos.

En el caso de los funcionarios administrativos, la aplicación del Reglamento Interno de Trabajo y la aplicación supletoria del Código de Trabajo hacen menos complejo el tratamiento de las diferentes situaciones de incumplimiento al contenido ético del contrato laboral. En todo caso, deberá imponerse un tratamiento casuístico de cada situación.

\section{LA DIMENSIÓN ÉTICA DEL PROBLEMA}

Más allá de los aspectos relacionados con la violación de los derechos de autor y los medios legales $y$ procesales para su afrontamiento, el tema del fraude literario es un problema ético.

Esto es así porque la amenaza de una sanción civil o incluso penal por su comisión no necesariamente funciona como incentivo negativo para su comisión. Quien deliberadamente incurre en fraude literario posiblemente se cree capaz de vencer el sistema de protección, es decir, de engañar o burlar exitosamente los controles dispuestos para la prevención y persecución de su acción.

Ahora bien, para que se configure una obra fraudulenta en el campo civil y sobre todo penal, se requiere del elemento volitivo del dolo, es decir, aquella voluntad tendiente a realizar la copia fraudulenta y su consecuente adjudicación de la autoría; en otras palabras, el querer de aquel resultado, el querer adjudicarse los méritos del producto de la inteligencia ajena con el consecuente perjuicio de aquel cuya obra ha sido utilizada sin su consentimiento, con la conciencia de que la obra sobre la cual ha ejecutado el fraude literario no es de su autoría. Otro elemento importante es el patrimonial como factor para la cuantificación económica del daño.

No obstante lo anterior, es posible llegar a ciertos resultados semejantes al latrocinio típico por la vía de la impericia y la desinformación. Por supuesto que la impericia elimina el dolo, $y$ aunque no es necesariamente susceptible de una valoración ética negativa, no elimina en nada la responsabilidad. Esta patología debe ser combatida por los Comités Asesores en el caso de los trabajos finales de graduación, o por los profesores en el caso de los trabajos rutinarios de los diferentes cursos. También pueden jugar ese papel los Consejos Científicos y las Comisiones de Investigación de las Unidades Académicas y de Investigación, a través de un adecuado control y seguimiento de las respectivas actividades de los docentes bajo su supervisión.

El tratamiento de los derechos de autor y el combate de la "pereza" y la deshonestidad metodológica en el nivel académico debe ser en alguna medida más rigurosa que el tratamiento legal ordinario, toda vez que es posible detectar 
otras patologías que no constituyen el fraude literario típico y que sin embargo, resultan inadmisibles desde el punto de vista ético y académico. Lamentablemente, podemos encontrar antecedentes reales de estas prácticas dentro de la Universidad de Costa Rica y débiles herramientas para su control $y$ afrontamiento.

Un primer fenómeno de este tipo se da cuando existe consentimiento del autor para el uso ilegítimo de su propia obra. Como pudo apreciarse, el autor tiene toda la potestad de autorizar la explotación de su obra; el derecho moral es inalienable e irrenunciable, por lo tanto, en buena técnica, debe afirmarse que no existe el derecho para consentir el "autoplagio"11 sobre su propia obra, porque como corolario de las características del derecho moral, los derechos de paternidad y de integridad de la obra no pueden ser renunciados ni cedidos. Más allá de esta discusión, lo relevante es que cuando se ejecuta una labor de investigación académica como requisito para actividades de evaluación de conocimientos, se asume que las mismas constituyen una obligación personalísima que no puede ser cumplida por un tercero. Este mismo argumento es aplicable, mutatis mutandi, a la investigación docente, sólo que en este caso lo que se evade es el cumplimiento de obligaciones laborales, también personalísimas y se violenta el contenido ético del contrato laboral.

Otra expresión de estos fenómenos, por desgracia nada extraña a nuestro contexto académico, se da cuando una persona, a cambio de una contraprestación, realiza obras que son presentadas bajo la autoría de un tercero, que en realidad no es más que un mandatario fraudulento. En el sentido apuntado, es posible que en alguna oportunidad hayan visto los bochornosos avisos de "Se hacen Tesis" alrededor del campus universitario, engalanados con algunos otros elementos que "garantizan" el producto final. Esta actividad es por supuesto académica y éticamente reprochable, aunque no constituya un fraude literario, propiamente dicho, en el sentido que se ha venido analizando por infringir los derechos de autor sin el consentimiento

11 Ver Balbuena, Pedro Virgilio. El Plagio como Ilícito Penal. op.cit. de aquel. En estos casos no se configura el fraude literario por cuanto no existe una apropiación clandestina del trabajo de un tercero, sino que aquel lo ha vendido. El mandatario no ha tenido la intención de violar el derecho de autor de aquel, sino que existe una colusión para engañar a la institución educativa respecto a la autoría del documento y a las condiciones del mandatario, que abriga el propósito de obtener el provecho o las ventajas de la obra.

\section{A MODO DE CONCLUSIÓN}

Para concluir este breve desarrollo es menester señalar que la creación de obras fraudulentas es una situación con repercusiones éticas, académicas y legales claramente definidas, cuya constatación y comprobación pueden revestir dificultades prácticas así como las medidas que pueden ser adoptadas.

En el momento de evaluar ese tipo de situaciones debe considerarse también la magnitud de la falta, las causas, esto es si el resultado puede ser atribuido a un ánimo doloso de engañar $y$ defraudar o a la impericia del investigador, a fin de sopesar los posibles remedios alternativos, como pueden ser las correcciones y la depuración o subsanación del trabajo o las medidas de corte más drásticas como la improbación del mismo y la aplicación de eventuales medidas disciplinarias de régimen estudiantil o laboral.

Es claro además que la Universidad de Costa Rica debe mejorar su reglamentación interna con el propósito de tipificar este tipo de comportamientos como falta a los efectos disciplinarios, tanto para el caso de estudiantes como profesores, pero también la formación metodológica, la inducción y la capacitación técnica y los procesos de control serio del trabajo académico y científico por parte de los órganos competentes tales como las Comisiones Editoriales, las Comisiones de Investigación de las respectivas Unidades Académicas o Académicas de Investigación o de los Consejos Científicos, según corresponda, sobre las actividades de investigación y difusión de conocimiento que realizan los investigadores, docentes $y$ en general los funcionarios universitarios, 
$y$ de los profesores sobre la labor de los estudiantes, cuando pueda o deba existir alguna injerencia, a fin de evitar, en la medida de lo posible, situaciones como las que se vienen analizando.

Además la sensibilización en el nivel ético a fin de crear una comunidad académica consciente de la importancia de la originalidad del quehacer intelectual, de la honestidad metodológica como valor del trabajo universitario $y$ de la integridad en todas las esferas de la vida como principios rectores de la vida en general. Esta formación ética, es sin duda parte de la formación universitaria para la vida.

\section{REFERENCIAS}

LIBROS

Castro Lobo, Manuel. Derechos de autor y derechos conexos en Costa Rica. San José. Alma Mater. 1. ed. 1999: 243.

Méndez Ramírez, Odilón. La investigación científica. $2^{\text {a }}$ ed. San José. IJSA, 2002: 221 ps.

REVISTAS

Hernández, Ma. Del Pilar. "El protocolo como instrumento de formalización del trabajo de investigación". Boletín Mexicano de Derecho Comparado 90. Nueva serie Xxx. México. Instituto de Investigaciones Jurídicas UNAM, setiembre-diciembre 2007: 1093-1118.

González Galván, José Alberto. "El protocolo de investigación jurídica”. Boletín Mexicano de Derecho Comparado 90. Nueva serie Xxx. México. Instituto de Investigaciones Jurídicas UNAM, setiembre-diciembre 2007: 1073-1087.
PONENCIAS

Romano, Rubén. "Transferencia de Tecnología y Propiedad de los Resultados de la Investigación en los Centros Universitarios. Titularidad y Transferencia de Tecnología”. Ponencia. Primer Seminario Internacional de propiedad Industrial, Intelectual y Nuevas Tecnologías, setiembre 2007. Universidad de Costa Rica, Facultad de Derecho y Programa de Educación Continua.

DICTÁMENES DE LA OFICINA JURÍDICA

Universidad de Costa Rica, Oficina Jurídica. oJ-0029-2005 del 11 de enero de 2005.

Universidad de Costa Rica, Oficina Jurídica. oJ-1271-2007 del 11 de octubre de 2007.

SITIOS WEB

Balbuena, Pedro Virgilio. "El plagio como ilícito penal”. (En línea) Ventana Legal Revista (VentanaLegal.com).En:<http://www. ventanalegal.com/revista_ventanalegal/ plagio_ilicito.htm>

Comunicado de la Comisión Interinstitucional de Propiedad Intelectual en el cual hace aclaraciones sobre los principales alcances de la legislación de derechos de autor en materia de reproducción de obras literarias con fines educativos. 17 de marzo de 2009 (en línea) En: <http://www.informatico.com/index.php?scc=articulo\&edic ion $=20090318 \&$ ref $=18-03-09020002>$

\section{BASES DE DATOS}

Master Lex. Leyes, Decretos y Reglamentos. 2005. 
